\title{
Diagnostic and prognostic value of HABP2 as a novel biomarker for endometrial cancer
}

\author{
Ying Jiang, Jinfeng Li, Cuiqin Sang, Guangming Cao, Shuzhen Wang \\ Department of Obstetrics and Gynecology, Beijing Chao-Yang Hospital, Capital Medical University, Beijing, China \\ Contributions: (I) Conception and design: Y Jiang, S Wang; (II) Administrative support: S Wang; (III) Provision of study materials or patients: J Li, C \\ Sang, G Cao; (IV) Collection and assembly of data: G Cao; (V) Data analysis and interpretation: Y Jiang, J Li, G Cao; (VI) Manuscript writing: All \\ authors; (VII) Final approval of manuscript: All authors. \\ Correspondence to: Shuzhen Wang. Department of Obstetrics and Gynecology, Beijing Chao-Yang Hospital, Capital Medical University, No.8 \\ GongrenTiyuchangNanlu, Chaoyang District, Beijing, China. Email: darrywang2003@163.com.
}

\begin{abstract}
Background: Endometrial cancer is the fifth most common malignant disorder in women, with its incidence increasing. A biomarker with diagnostic and prognostic value remains to be found. The HABP2 protein, or Factor VII-activating protease, encodes a hyaluronic acid-binding protein.

Methods: Patient data including clinical characteristics and RNAseq information of HABP2 was obtained from The Cancer Genome Atlas (TCGA), and analyzed by R statistic packages. A total of 370 women with endometrial cancer were enrolled in the study. To study the diagnostic value of HABP2 in patients with endometrial cancer, receiver operating characteristic (ROC) curves were plotted by the pROC package. To study the prognostic value of HABP2 in patients with endometrial cancer, the survival package in $\mathrm{R}$ was used and the Cox model was established.
\end{abstract}

Results: HABP2 expression was lower in endometrial cancer compared with normal endometrial tissues. HABP2 showed moderate diagnostic value for endometrial cancer, with HBP2 expression associated with vital status, histologic grade, and residual tumor. HABP2 was an independent prognostic factor, with low HABP2 expression indicating a better overall survival.

Conclusions: HABP2 has diagnostic and prognostic value and maybe a novel biomarker for endometrial cancer.

Keywords: Endometrial cancer; HABP2; diagnosis; prognosis; biomarker

Submitted Jul 10, 2020. Accepted for publication Sep 03, 2020.

doi: $10.21037 / \mathrm{atm}-20-5744$

View this article at: http://dx.doi.org/10.21037/atm-20-5744

\section{Introduction}

Endometrial cancer is the fifth most prevalent malignant disorder in women, with its morbidity rate increasing (1-3). The cumulative risk of women developing endometrial cancer by age 75 is $1 \%$, and $0.2 \%$ for death (4). In developed countries, endometrial cancer is the most prevalent gynaecological tumor, however it is less prevalent in developed countries $(1,2)$. Endometrial cancer generally occurs in postmenopausal women, while $14 \%$ are premenopausal, and $5 \%$ are less than 40 years old (5). Several factors may be associated with endometrial cancer, including obesity, diabetes, and age (2). Endometrial carcinoma have increased markedly over the last decades. Although the majority of women with endometrial carcinoma have good outcomes, women with advanced disease or more aggressive subtypes may not be curable with adjuvant therapy. we are in desperate need of new approaches, including diagnostic tools, to manage this cancer. There are many unanswered questions in endometrial carcinoma pertaining to diagnosis and optimal management.

The plasma protein HABP2, also known as Factor VIIactivating protease, encodes a hyaluronic acid-binding protein (6). HABP2 degrades the extracellular matrix and 
functions in coagulation via activating Factor VII and pro-urokinase $(6,7)$. More importantly, HABP2 exhibits a tumor-suppressive effect in epithelial cells (8). Most studies of HABP2 have focused on thyroid cancer, especially familial non-medullary thyroid cancers (8-12). There are few reports on the role of HABP2 in endometrial cancer. This is the first study of HABP2 as a potential novel biomarker in endometrial cancer. Molecular classification of endometrial cancer (copy number low/p53 wild-type, copy number high/p53 abnormal, polymerase E mutant, and mismatch repair deficient) has shown great promise, proving to be reproducible, and demonstrating associations with clinical outcomes. Unfortunately, to identify these four genomic subgroups, including genome sequencing, were costly, complex and unsuitable for wider clinical application. Our study aimed was to determine whether the some molecular subgroups could be identified and the survival curves reproduced with assays that could be used in routine clinical practice.

Herein, the expression of HABP2 in patients with endometrial cancer was assessed and related clinical features examined. The diagnostic and prognostic values of HABP2 were evaluated using receiver operating characteristic (ROC) curves and Cox model analysis, respectively. We present the following article in accordance with the REMARK reporting checklist (available at http://dx.doi. org/10.21037/atm-20-5744).

\section{Methods}

\section{Data mining}

Data from patients suffering from endometrial cancer, including clinical characteristics and RNSseq of HABP2, were downloaded from The Cancer Genome Atlas (TCGA) database by UCSC Xena. TCGA is open to the public and no ethics approval was required. The study was conducted in accordance with the Declaration of Helsinki (as revised in 2013) and was approved by the Ethic Committee of Beijing Chao-Yang Hospital (No. 2019-331).

A total number of 370 women with endometrial cancer, comprising 72 women below the age of 55 and 298 women over the age of 55 and over, were enrolled in the study.

\section{Software}

$\mathrm{R}$ version 3.5.2 packages were used for bioinformatics analysis.

\section{Evaluation of RNA expression}

The RNA expression of HABP2 is shown in boxplots. Vertical lines represent $95 \%$ confidence intervals (CI).

\section{Evaluation of diagnostic value}

ROC curves were plotted by pROC package (13). The calculated area under the curves (AUC) indicated the diagnostic value. The high and low expression were grouped according to the identified threshold level of HABP2.

\section{Evaluation of prognostic value}

The R survival package and Cox model were established (14) and evaluation of sub-groups were performed.

\section{Statistical analysis}

The Wilcoxon rank-sum examination was used to compare the two groups. The Kruskal-Wallis examination was involved in comparing differences between three or more groups. The chi-squared test was performed, and corrected by Fisher's exact test. A P value of less than 0.05 was considered statistically significant.

\section{Results}

\section{Characteristics of patients}

Clinical information including age, histology, stage, diabetes, hypertension, histologic grade, menopause status, residual tumor, vital status, HABP2 expression, overall survival, and recurrence-free survival are shown in Table 1 . The histological type of most patients was endometrioid $(81.89 \%)$, and $65.95 \%$ of the patients had stage 1 disease. Nearly one quarter of patients suffered from diabetes, and one half suffered from hypertension. The histologic grade with the highest incidence rate was G3. Most women were post-menopause (81.08\%).

\section{High HABP2 expression in tumor}

Compared with normal tissue, HABP2 was found to highly expressed in endometrial tumors $(\mathrm{P}=0.017$; Figure 1A). Furthermore, the association of HABP2 expression with histological type, stage, histologic grade, age, diabetes, hypertension, menopause status, residual 
Table 1 Clinical characteristics of the patients with endometrial cancer

\begin{tabular}{|c|c|}
\hline Characteristics & Number (\%) \\
\hline \multicolumn{2}{|l|}{ Age } \\
\hline$<55$ & $72(19.46)$ \\
\hline$\geq 55$ & $298(80.54)$ \\
\hline \multicolumn{2}{|l|}{ Histological type } \\
\hline Endometrioid & $303(81.89)$ \\
\hline Mixed & $10(2.70)$ \\
\hline Serous & $57(15.41)$ \\
\hline \multicolumn{2}{|l|}{ Stage } \\
\hline I & $244(65.95)$ \\
\hline II & $28(7.57)$ \\
\hline III & 79 (21.35) \\
\hline IV & $19(5.14)$ \\
\hline \multicolumn{2}{|l|}{ Diabetes } \\
\hline No & 209 (56.49) \\
\hline Yes & $84(22.7)$ \\
\hline NA & $77(20.81)$ \\
\hline \multicolumn{2}{|l|}{ Hypertension } \\
\hline No & 127 (34.32) \\
\hline Yes & $188(50.81)$ \\
\hline NA & $55(14.86)$ \\
\hline \multicolumn{2}{|l|}{ Histologic grade } \\
\hline G1 & $85(22.97)$ \\
\hline G2 & $100(27.03)$ \\
\hline G3 & $178(48.11)$ \\
\hline High grade & 7 (1.89) \\
\hline \multicolumn{2}{|l|}{ Menopause status } \\
\hline Indeterminate & $14(3.78)$ \\
\hline Peri-menopause & $14(3.78)$ \\
\hline Post-menopause & $300(81.08)$ \\
\hline Pre-menopause & $26(7.03)$ \\
\hline NA & $16(4.32)$ \\
\hline \multicolumn{2}{|l|}{ Residual tumor } \\
\hline $\mathrm{R}_{0}$ & $265(71.62)$ \\
\hline $\mathrm{R}_{1}$ & $18(4.86)$ \\
\hline
\end{tabular}

Table 1 (continued)
Table 1 (continued)

\begin{tabular}{lc}
\hline Characteristics & Number (\%) \\
\hline $\mathrm{R}_{2}$ & $11(2.97)$ \\
$\mathrm{R}_{\mathrm{x}}$ & $23(6.22)$ \\
$\mathrm{NA}$ & $53(14.32)$ \\
Vital status & \\
Deceased & $58(15.68)$ \\
Living & $312(84.32)$ \\
HABP2 & \\
High & $188(50.81)$ \\
Low & $182(49.19)$ \\
Overall survival & \\
No & $58(15.68)$ \\
Yes & $312(84.32)$ \\
Recurrence-free survival & \\
No & $73(19.73)$ \\
Yes & $297(80.27)$ \\
\hline
\end{tabular}

tumor and vital status was evaluated in endothelial tumors (Figure $1 B, C, D, E, F, G, H, I, \mathcal{F}$ ). As shown in Figure $1 D$, the histologic grade of G3 showed the lowest HABP2 expression, and G1 showed the highest HABP2 expression $(\mathrm{P}=1.2 \mathrm{e}-15)$. The HABP2 expression in high grade was close to that in G2, between G3 and G1. As for residual tumor, the HABP2 expression of the most common $\mathrm{R}_{0}$ (71.62\%; Table 1) was higher than $\mathrm{R}_{2}$ and $\mathrm{R}_{1}(\mathrm{P}=0.03)$. No significant were found in other subgroup analyses.

\section{Diagnostic value of HABP2 for endometrial cancer}

The ROC analysis was first performed in all patients, indicating a modest diagnostic value with AUC of 0.711 (Figure $2 A$ ). Then, different stages of endometrial cancer were further analyzed (Figure $2 B, C, D, E$ ). Results showed that the diagnostic value was decreasing with stage, with the AUC increasing from stage I (AUC $=0.726$ ) to stage II (AUC $=0.711)$ to stage III (AUC $=0.685)$ finally to stage IV (AUC $=0.629)$.

\section{Correlation of HABP2 expression with clinical features}

Patients were divided into high HABP2 $(\mathrm{n}=188)$ and low 

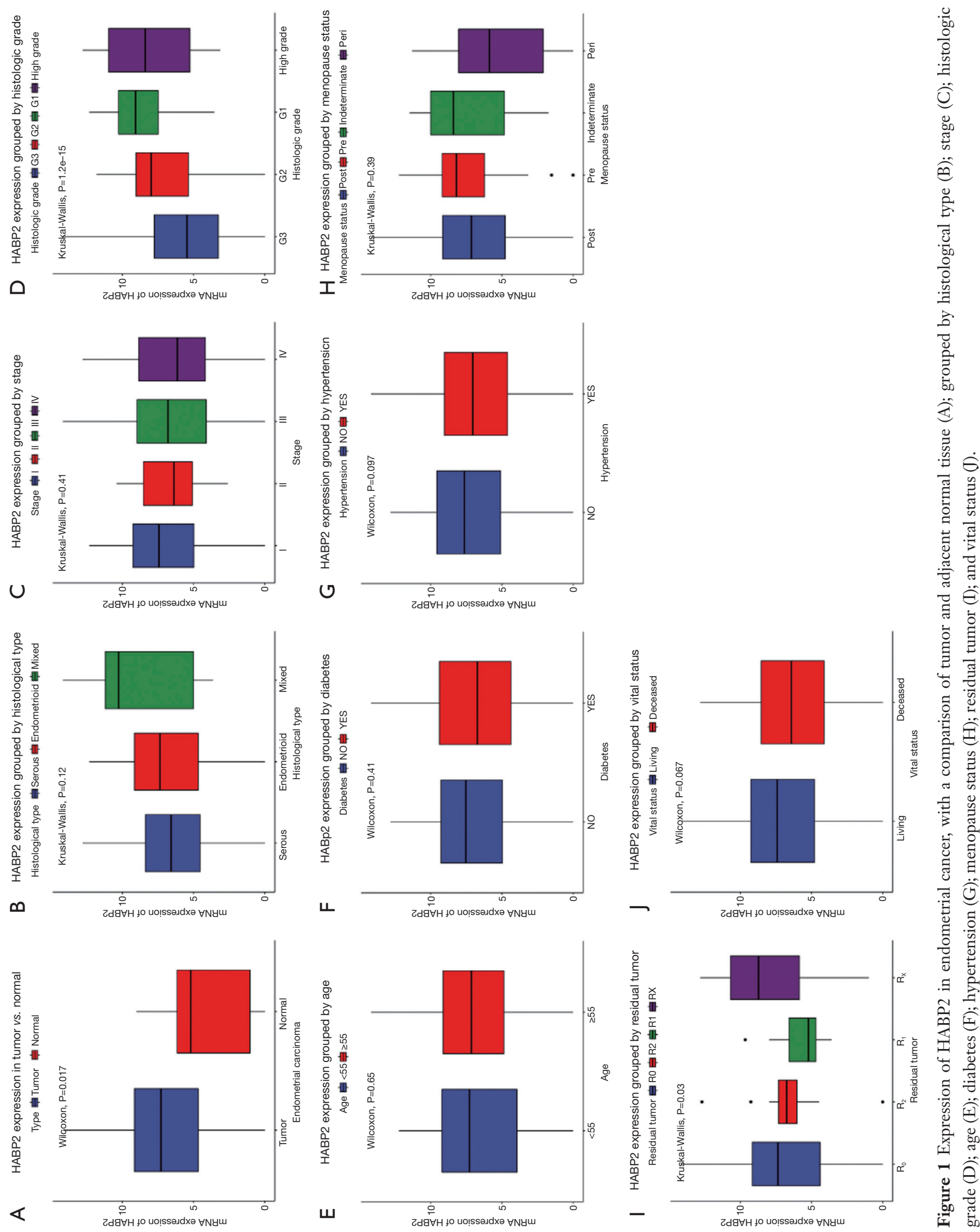

$$
\text { }
$$



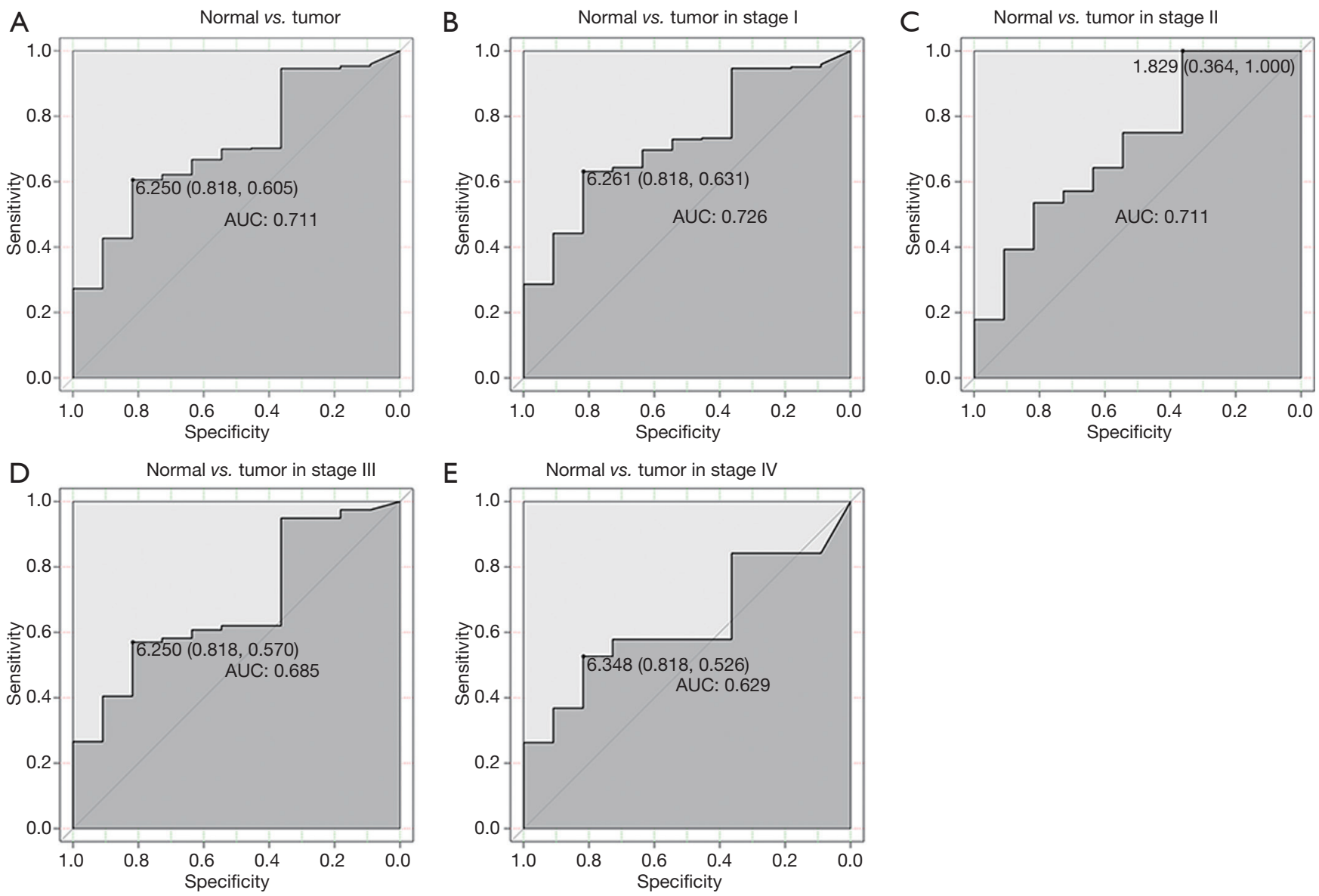

Figure 2 ROC (Receiver operating characteristic) curves of HABP2 expression in patients with endometrial cancer, including normal vs. overall tumor (A); normal vs. stage I tumor (B); normal vs. stage II tumor (C); normal vs. stage III tumor (D); and normal vs. stage IV tumor $(\mathrm{E})$.

HABP2 ( $\mathrm{n}=182)$ expression groups. As shown in Table 2, HABP2 expression was associated with vital status $(\mathrm{P}=0.023)$, histologic grade $(\mathrm{P}<0.001)$, and residual tumor $(\mathrm{P}=0.007)$. No association was found between HABP2 expression and age $(\mathrm{P}=0.982)$, histological type $(\mathrm{P}=0.312)$, stage $(\mathrm{P}=0.481)$, diabetes $(\mathrm{P}=0.616)$, hypertension $(\mathrm{P}=0.314)$, and menopause status $(\mathrm{P}=0.626)$.

\section{Prognostic value of HABP2 for endometrial cancer}

Given that HABP2 was correlated with survival, the prognostic value of HABP2 was further studied. As shown in Figure 3A, patients with low HABP2 expression presented an improved overall survival rate $(\mathrm{P}=0.0027)$. Analysis of subgroups (patients in different age, stage and grade) showed that HABP2 had significant prognostic value in $\mathrm{G} 3$ and $\mathrm{G} 4(\mathrm{P}=0.037)$ and elderly patients (patients older than 55 years) $(\mathrm{P}=0.00061)$ (Figure 3B, C,D,E,F,G).

A univariate Cox model was established (Table 3). No obvious differences were observed in relation to diabetes $(\mathrm{P}=0.619)$, histologic grade $(\mathrm{P}=0.329)$, histological type $(\mathrm{P}=0.248)$, hypertension $(\mathrm{P}=0.887)$, residual tumor $(\mathrm{P}=0.183)$ and stage $(\mathrm{P}=0.561)$. Age $(\mathrm{P}=0.021)$ and menopause status $(\mathrm{P}=0.017)$ showed significant differences. HABP2 may be a risk factor $(\mathrm{HR}=1.41 ; \mathrm{P}=0.003)$. As shown in Table 4, the multivariate analysis further confirmed HABP2 was a risk factor and an independent prognostic indicator for overall survival (HR $=1.37 ; 95 \% \mathrm{CI}: 1.09-1.73 ; \mathrm{P}=0.008)$.

\section{Discussion}

In this bioinformatics study, HABP2 was shown to be highly 
Table 2 Relationship between the clinical features and HABP2 expression in patients with endometrial cancer

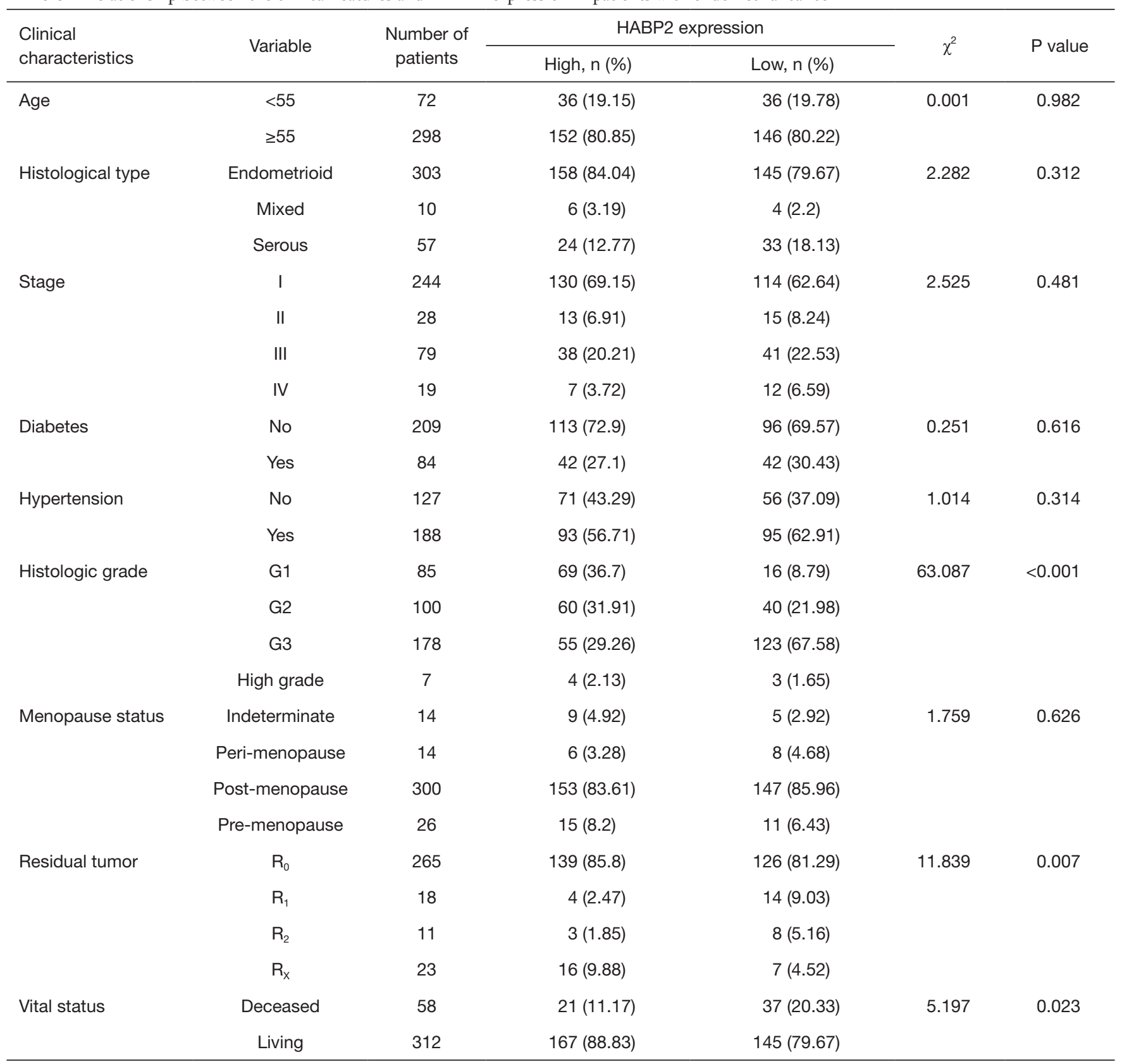

expressed in endometrial cancer. HABP2 expression was associated with vital status, histologic grade, and residual tumor type. Although diabetes and menopause status are highly related with endometrial tissue, no association was found between these and HABP2 expression. Further, HABP2 presented a moderate diagnostic value for endometrial cancer.

The HABP2 gene mutation has been commonly studied in thyroid cancer (10), and the HABP2 variant is a susceptibility gene for familial non-medullary thyroid cancer (7). HABP2 has also been studied in lung cancer (15), atherosclerosis (16), deep venous thrombosis (17), and female infertility (18). A study conducted by Mirzapoiazova et al. suggested that HABP2 may directly activate uPA and promote lung cancer progression (15). Increased HABP2 expression has been observed in tissue of different 

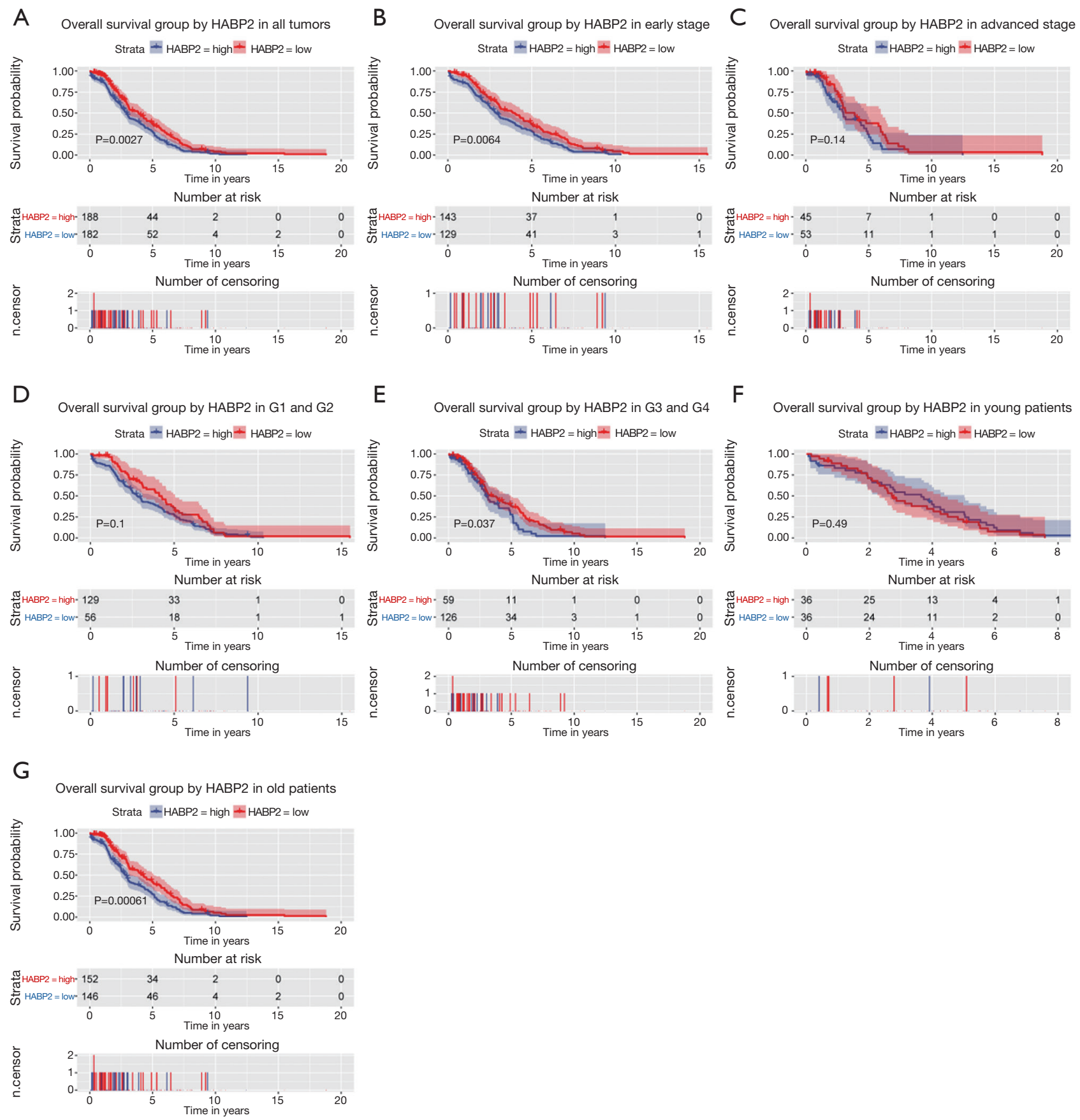

Figure 3 Relationship of HABP2 expression with overall survival in all patients with endometrial cancer (A); patients in early stage (B); patients in advanced stage (C); patients in G1 and G2 (D); patients in G3 and G4 (E); young patients (F); and elderly patients (G).

non-small cell lung cancer (15). HABP2 regulates cell proliferation mediated by growth factor and migration $(19,20)$. Additionally, HABP2 regulates the function of endothelial cells, including vascular integrity and neointima formation $(21,22)$.
In recent years, biomarker research by data mining has become popular (23-34). The exploration of biomarkers for endometrial cancer is ongoing. Abnormal expression of PICT-1 is a risk factor for human endometrial cancer (35). PTEN expression, reported by Yang et al., may also be a risk 
Table 3 Univariate analysis of overall survival in patients with endometrial cancer

\begin{tabular}{lccc}
\hline Parameters & Hazard ratio & $95 \% \mathrm{Cl}$ & $\mathrm{P}$ value \\
\hline Age & 0.72 & $0.55-0.95$ & 0.021 \\
Diabetes & 0.96 & $0.81-1.13$ & 0.619 \\
HABP2 & 1.41 & $1.13-1.76$ & 0.003 \\
Histologic grade & 0.94 & $0.82-1.07$ & 0.329 \\
Histological type & 0.91 & $0.77-1.07$ & 0.248 \\
Hypertension & 0.99 & $0.85-1.15$ & 0.887 \\
Menopause status & 0.85 & $0.75-0.97$ & 0.017 \\
Residual tumor & 1.09 & $0.96-1.23$ & 0.183 \\
Stage & 0.96 & $0.85-1.09$ & 0.561 \\
\hline
\end{tabular}

Table 4 Multivariate analysis of overall survival in patients with endometrial cancer

\begin{tabular}{lccc}
\hline Parameters & Hazard ratio & $95 \% \mathrm{Cl}$ & P value \\
\hline Age & 0.82 & $0.57-1.18$ & 0.281 \\
HABP2 & 1.37 & $1.09-1.73$ & 0.008 \\
Menopause status & 0.93 & $0.78-1.1$ & 0.382 \\
\hline
\end{tabular}

factor (36). Merritt et al. studied the association of Insulin/ IGF (insulin-like growth factor) and sex hormones with risk factors (37). We reported HABP2 to be a risk factor for endometrial cancer.

From our results, HABP2 is a risk factor for endometrial cancer, and low HABP2 expression is associated with better overall survival. HABP2 is suggested to effect endometrial receptivity for embryo implantation(38). HABP2 has been shown to be down-regulated in sub-fertile women, women with refractory conditions, and unexplained infertility (18). As observed by Altmae et al., HABP2 is involved in the angiogenesis and extracellular matrix degradation of endometrium cells (18). These findings indicate that HABP2 may significantly affect the function of the endometrium and further be involved in the development, progress and metastasis of endometrial cancer.

Our research first suggests a diagnostic and prognostic value of HABP2 for endometrial cancer. The major limitation is that this study analyzed the data from a single database. Further verifications in different areas and populations are required. Additional in vivo and in vitro function experiments and exploration of its molecular mechanism would further illuminate the role of HABP2 in endometrial cancer.

\section{Conclusions}

In conclusion, HABP2 was lower expressed in endometrial cancer in comparison with normal endometrial tissues. HABP2 expression was associated with vital status, histologic grade and residual tumor. HABP2 had a moderate diagnostic value for endometrial cancer. HABP2 was an independent prognostic factor and low HABP2 expression indicated a better overall survival. HABP2 may be a novel biomarker for endometrial cancer.

\section{Acknowledgments}

Funding: This study was supported by the Capital Citizen Health Cultivation Project (no. 161100000116077), Key Projects of Sailing Plan of Beijing Medical Administration (no. ZYLX201713).

\section{Footnote}

Reporting Checklist: The authors have completed the REMARK reporting checklist. Available at http://dx.doi. org/10.21037/atm-20-5744 
Conflicts of Interest: All authors have completed the ICMJE uniform disclosure form (available at http://dx.doi. org/10.21037/atm-20-5744). The authors have no conflicts of interest to declare.

Etbical Statement: The authors are accountable for all aspects of the working ensuring that questions related to the accuracy or integrity of any part of the work are appropriately investigated and resolved. The study was conducted in accordance with the Declaration of Helsinki (as revised in 2013) and was approved by the Ethic Committee of Beijing Chao-Yang Hospital (No. 2019-331). Individual informed consent was waived.

Open Access Statement: This is an Open Access article distributed in accordance with the Creative Commons Attribution-NonCommercial-NoDerivs 4.0 International License (CC BY-NC-ND 4.0), which permits the noncommercial replication and distribution of the article with the strict proviso that no changes or edits are made and the original work is properly cited (including links to both the formal publication through the relevant DOI and the license). See: https://creativecommons.org/licenses/by-nc-nd/4.0/.

\section{References}

1. Amant F, Moerman P, Neven P, et al. Endometrial cancer. Lancet 2005;366:491-505.

2. Paucarmayta A, Taitz H, Casablanca Y, et al. TGF- $\beta$ signaling proteins and CYP24A1 may serve as surrogate markers for progesterone calcitriol treatment in ovarian and endometrial cancers of different histological types. Transl Cancer Res 2019;8:1423-37.

3. Corrado G, Bruni S, Vizza E. Robotic surgery in earlystage endometrial cancer. Transl Cancer Res 2019;8:S573-6.

4. Ferlay J, Soerjomataram I, Dikshit R, et al. Cancer incidence and mortality worldwide: sources, methods and major patterns in GLOBOCAN 2012. Int J Cancer 2015;136:E359-86.

5. Lee TS, Jung JY, Kim JW, et al. Feasibility of ovarian preservation in patients with early stage endometrial carcinoma. Gynecol Oncol 2007;104:52-7.

6. Kern B, Coppin L, Romanet P, et al. Multiple HABP2 variants in familial papillary thyroid carcinoma: Contribution of a group of "thyroid-checked" controls. Eur J Med Genet 2017;60:178-84.
7. Colombo C, Muzza M, Proverbio MC, et al. Segregation and expression analyses of hyaluronan-binding protein 2 (HABP2): insights from a large series of familial nonmedullary thyroid cancers and literature review. Clin Endocrinol (Oxf) 2017;86:837-44.

8. Gara SK, Jia L, Merino MJ, et al. Germline HABP2 Mutation Causing Familial Nonmedullary Thyroid Cancer. N Engl J Med 2015;373:448-55.

9. Weeks AL, Wilson SG, Ward L, et al. HABP2 germline variants are uncommon in familial nonmedullary thyroid cancer. BMC Med Genet 2016;17:60.

10. Alzahrani AS, Murugan AK, Qasem E, et al. HABP2 Gene Mutations Do Not Cause Familial or Sporadic NonMedullary Thyroid Cancer in a Highly Inbred Middle Eastern Population. Thyroid 2016;26:667-71.

11. Zhang T, Xing M. HABP2 G534E Mutation in Familial Nonmedullary Thyroid Cancer. J Natl Cancer Inst 2016;108:djv415.

12. Cantara S, Marzocchi C, Castagna MG, et al. HABP2 G534E variation in familial non-medullary thyroid cancer: an Italian series. J Endocrinol Invest 2017;40:557-60.

13. Robin X, Turck N, Hainard A, et al. pROC: an opensource package for $\mathrm{R}$ and $\mathrm{S}+$ to analyze and compare ROC curves. BMC Bioinformatics 2011;12:77.

14. Moreno-Betancur M, Sadaoui H, Piffaretti C, et al. Survival Analysis with Multiple Causes of Death: Extending the Competing Risks Model. Epidemiology 2017;28:12-9.

15. Mirzapoiazova T, Mambetsariev N, Lennon FE, et al. HABP2 is a Novel Regulator of Hyaluronan-Mediated Human Lung Cancer Progression. Front Oncol 2015;5:164.

16. Kanse SM, Parahuleva M, Muhl L, et al. Factor VIIactivating protease (FSAP): vascular functions and role in atherosclerosis. Thromb Haemost 2008;99:286-9.

17. Sidelmann JJ, Vitzthum F, Funding E, et al. Factor VIIactivating protease in patients with acute deep venous thrombosis. Thromb Res 2008;122:848-53.

18. Altmae S, Kallak TK, Friden B, et al. Variation in hyaluronan-binding protein 2 (HABP2) promoter region is associated with unexplained female infertility. Reprod Sci 2011;18:485-92.

19. Christian Kannemeier NA-F, Klaus T. Preissner, Sandip M. Kanse. Factor VII activating protease (FSAP) inhibits growth factor-mediated cell proliferation and migration of vascular smooth muscle cells. The FASEB Journal 2004;18:728-30. 
20. Etscheid M, Beer N, Dodt J. The hyaluronan-binding protease upregulates ERK1/2 and PI3K/Akt signalling pathways in fibroblasts and stimulates cell proliferation and migration. Cell Signal 2005;17:1486-94.

21. Mambetsariev N, Mirzapoiazova T, Mambetsariev B, et al. Hyaluronic Acid binding protein 2 is a novel regulator of vascular integrity. Arterioscler Thromb Vasc Biol 2010;30:483-90.

22. Sedding D, Daniel JM, Muhl L, et al. The G534E polymorphism of the gene encoding the factor VIIactivating protease is associated with cardiovascular risk due to increased neointima formation. J Exp Med 2006;203:2801-7.

23. Cai H, Jiao Y, Li Y, et al. Low CYP24A1 mRNA expression and its role in prognosis of breast cancer. Sci Rep 2019;9:13714.

24. Cui Y, Jiao Y, Wang K, et al. A new prognostic factor of breast cancer: High carboxyl ester lipase expression related to poor survival. Cancer Genet 2019;239:54-61.

25. Fu Z, Jiao Y, Li YQ, et al. PES1 In Liver Cancer: A Prognostic Biomarker With Tumorigenic Roles. Cancer Manag Res 2019;11:9641-53.

26. Jiao Y, Fu Z, Li Y, et al. High EIF2B5 mRNA expression and its prognostic significance in liver cancer: a study based on the TCGA and GEO database. Cancer Manag Res 2018;10:6003-14.

27. Jiao Y, Fu Z, Li Y, et al. Aberrant FAM64A mRNA expression is an independent predictor of poor survival in pancreatic cancer. PLoS One 2019;14:e0211291.

28. Jiao Y, Li Y, Fu Z, et al. OGDHL Expression as a Prognostic Biomarker for Liver Cancer Patients. Dis Markers 2019;2019:9037131.

29. Jiao Y, Li Y, Ji B, et al. Clinical Value of lncRNA LUCAT1 Expression in Liver Cancer and its Potential Pathways. J

Cite this article as: Jiang Y, Li J, Sang C, Cao G, Wang S. Diagnostic and prognostic value of HABP2 as a novel biomarker for endometrial cancer. Ann Transl Med 2020;8(18):1164. doi: 10.21037/atm-20-5744
Gastrointestin Liver Dis 2019;28:439-47.

30. Jiao Y, Li Y, Jiang P, et al. PGM5: a novel diagnostic and prognostic biomarker for liver cancer. PeerJ 2019;7:e7070.

31. Jiao Y, Li Y, Lu Z, et al. High Trophinin-Associated Protein Expression Is an Independent Predictor of Poor Survival in Liver Cancer. Dig Dis Sci 2019;64:137-43.

32. Li Y, Jiao Y, Fu Z, et al. High miR-454-3p expression predicts poor prognosis in hepatocellular carcinoma. Cancer Manag Res 2019;11:2795-802.

33. Zhao YC, Jiao Y, Li YQ, et al. Elevated high mobility group A2 expression in liver cancer predicts poor patient survival. Rev Esp Enferm Dig 2020;112:27-33.

34. Zhou LL, Jiao Y, Chen HM, et al. Differentially expressed long noncoding RNAs and regulatory mechanism of LINC02407 in human gastric adenocarcinoma. World J Gastroenterol 2019;25:5973-90.

35. Yoshimoto M, Tokuda A, Nishiwaki K, et al. Abnormal Expression of PICT-1 and Its Codon 389 Polymorphism Is a Risk Factor for Human Endometrial Cancer. Oncology 2018;95:43-51.

36. Yang HP, Meeker A, Guido R, et al. PTEN expression in benign human endometrial tissue and cancer in relation to endometrial cancer risk factors. Cancer Causes Control 2015;26:1729-36.

37. Merritt MA, Strickler HD, Einstein MH, et al. Insulin/ IGF and sex hormone axes in human endometrium and associations with endometrial cancer risk factors. Cancer Causes Control 2016;27:737-48.

38. Horcajadas JA, Pellicer A, Simon C. Wide genomic analysis of human endometrial receptivity: new times, new opportunities. Hum Reprod Update 2007;13:77-86.

(English Language Editor: J. Brown) 